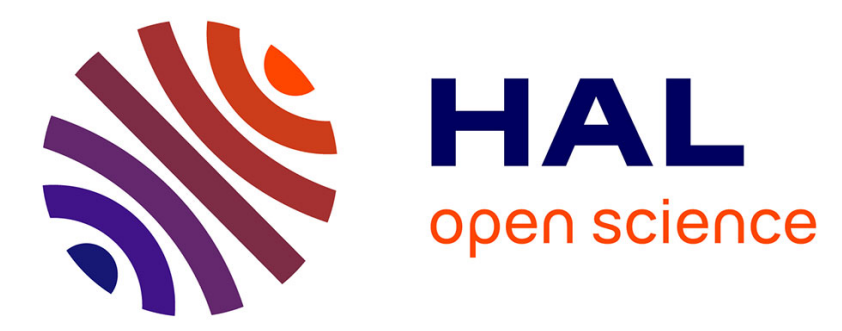

\title{
How best to treat older patients with metastatic colorectal cancer?
}

\author{
Julien Taieb
}

\section{To cite this version:}

Julien Taieb. How best to treat older patients with metastatic colorectal cancer?. The Lancet Gastroenterology \& Hepatology, 2019, 4, pp.331 - 333. 10.1016/S2468-1253(19)30076-7 . hal-03486589

\section{HAL Id: hal-03486589 \\ https://hal.science/hal-03486589}

Submitted on 20 Dec 2021

HAL is a multi-disciplinary open access archive for the deposit and dissemination of scientific research documents, whether they are published or not. The documents may come from teaching and research institutions in France or abroad, or from public or private research centers.
L'archive ouverte pluridisciplinaire HAL, est destinée au dépôt et à la diffusion de documents scientifiques de niveau recherche, publiés ou non, émanant des établissements d'enseignement et de recherche français ou étrangers, des laboratoires publics ou privés.

\section{다)(1) $(5$}

Distributed under a Creative Commons Attribution - NonCommerciall 4.0 International 


\title{
How to best treat elderly patients with metastatic colorectal cancer?
}

\author{
Correspondence:
}

Pr Julien Taieb, Georges Pompidou European Hospital, Department of hepatogastroenterology and GI oncology, Sorbonne Paris Cité / Université Paris Descartes, 20 rue Leblanc 75015 Paris, France Phone: 331 56093551; Fax: 331 56093441 julien.taieb@aphp.fr / jtaieb75@gmail.com

More than $50 \%$ of cases of metastatic colorectal cancer (mCRC) in western countries occur in patients over 70 years old (1). However, while the search term matches "colorectal cancer" and "elderly" (PubMed) yield more than 4000 published articles for every year since 2013, very few prospective controlled trials have been performed in this patient population. One such study is that of Winther et al. entitled "Dose-reduced combination chemotherapy (S-1 + oxaliplatin) versus full-dose monotherapy (S-1) in older vulnerable patients with metastatic colorectal cancer (NORDIC 9): a randomised, open-label phase II trial" (2).

The problem raised by this specific population is linked first to the potential comorbidities and poor life expectancy of these patients, but also to their potentially worse treatment tolerability, which may lead to quality of life impairment, reduced dose intensity and subsequent partial or complete loss of treatment efficacy.

For these reasons, these patients are generally not enrolled or poorly represented in registration clinical trials, though data on this population are of major importance. From national cohorts, it has been reported that less than half of mCRC patients over 75 years old receive chemotherapy (as compared to $85 \%$ in younger patients) and that a single agent is used in more than $30 \%$ of cases (as compared to $10 \%$ in younger patients)(3).

Before the publication of the NORDIC 9 trial, 4 main trials assessed chemotherapeutic approaches in mCRC patients over 70 or 75 . FFCD-2001 and FOCUS2 failed to demonstrate a significant benefit of adding irinotecan or oxaliplatin to 5FU or capecitabine, in first-line treatment, and showed increased toxicity when combination chemotherapy or capecitabine was used $(4,5)$. The AVEX trial showed that PFS improved with the addition of bevacizumab 
to capecitabine, and the PRODIGE 20 trial showed a trend to better PFS with the addition of bevacizumab to $5 \mathrm{FU}(6,7)$.

Interestingly, NORDIC 9 was the first trial to assess the use of a doublet chemotherapeutic regimen with possibly practice-changing results. Its clever design, which compared full-dose monotherapy with dose-reduced combination therapy, is probably one key to its success. In fact, all previously mentioned trials used the same dose of fluoropyrimidine backbones in both arms. This design allowed, for the first time, improved PFS without increased toxicity with the use of combination chemotherapy.

Though dose-reduced S1+oxaliplatin therefore seems to be an attractive option for elderly mCRC patients, it has to be said that $\mathrm{S} 1$ is not available in many countries, especially in Europe, and this may limit the impact of these results in the future. Moreover, the superiority of $\mathrm{S} 1$ versus standard infusional 5FU has never been proven in mCRC patients in western countries. And the idea of using dose-reduced infusional 5FU combined with oxaliplatin or even irinotecan should also be explored.

One limitation of the NORDIC 9 trial is that though it is stated that the trial was dedicated to "older vulnerable patients", i) only patients above 70 years of age were enrolled, though 75 is nowadays the preferred cut-off to characterize elderly patients, and ii) vulnerability scores were not among the inclusion criteria. When looking at the results, we can even see that only 22 to $27 \%$ of the enrolled patients were vulnerable as per the VES-13 and G8 assessments.

Finally, NORDIC 9 and all the other previously mentioned oncogeriatric trials in mCRC patients failed to show any significant benefit in OS, even though a non-significant trend was observed, as previously reported in the AVEX and PRODIGE 20 trials. OS in all these trials was a disappointing 13 to 19 months, which is far from the 25 to 35 months generally reported in mCRC.

To conclude, the good signals observed with the addition of oxaliplatin and bevacizumab to a fluoropyrimidine-based chemotherapeutic regimen in elderly patients with mCRC should now motivate academic groups to design an ambitious, international and sufficiently powered randomised controlled trial in patients over 75 years old with documented vulnerability as an inclusion criterion, with a view to improving the poor OS constantly reported in this patient population. 
references

1. http://www.ncin.org.uk/cancer_information_tools/ukcis

2. Stine Braendegaard Winther, Gabor Liposits, Halla Skuladottir et al. Dose-reduced combination chemotherapy (S-1 + oxaliplatin) versus full-dose monotherapy (S1) in older vulnerable patients with metastatic colorectal cancer (NORDIC9): a randomised, open-label phase II trial. Lancet hepatogastenrteol.

3. Doat S, Thiébaut A, Samson S et al. Elderly patients with colorectal cancer: treatment modalities and survival in France. National data from the ThInDiT cohort study. Eur J Cancer. 2014;50(7):1276-83.

4. Aparicio T, Lavau-Denes S, Phelip JM, et al. Randomized phase III trial in elderly patients comparing LV5FU2 with or without irinotecan for first-line treatment of metastatic colorectal cancer (FFCD 2001-02). Ann Oncol 2016; 27: 121-7.

5. Seymour MT, Thompson LC, Wasan HS, et al. Chemotherapy options in elderly and frail patients with metastatic colorectal cancer (MRC FOCUS2): an open-label, randomised factorial trial. Lancet 2011; 377: 1749-59.

6. Aparicio T, Bouche 0 , Taieb J, et al. Bevacizumab+chemotherapy versus chemotherapy alone in elderly patients with untreated metastatic colorectal cancer: a randomized phase II trial-PRODIGE 20study results. Ann Oncol 2018; 29: 133-8.

7. Cunningham D, Lang I, Marcuello E, et al. Bevacizumab plus capecitabine versus capecitabine alone in elderly patients with previously untreated metastatic colorectal cancer (AVEX): anopen-label, randomised phase 3 trial. Lancet Oncol 2013; 14: 1077-85. 